\section{Sulfoconjugation of Bisphenol A in a Human Neuroblastoma Cell Line, NB-1}

\author{
Yoshio Ishii and Hiro-omi Tamura* \\ Kyoritsu College of Pharmacy, 1-5-30, Shibakoen, Minatoku, \\ Tokyo 105-8512, Japan \\ (Received March 27, 2003; Accepted April 10, 2003)
}

Bisphenol A (BPA) is a common environmental endocrine disruptor and BPA sulfate has been demonstrated as one of metabolites of BPA. Since it has been observed to have effects on the central nervous system (CNS), we examined the effects of sulfoconjugation on the toxicity of BPA in a human neuroblastoma cell line, NB-1. NB-1 cells showed limited but significant sulfotransferase activity toward BPA in vitro $(\mathrm{Km}=$ $74 \mu \mathrm{M}, \mathrm{Vmax}=7.8 \mathrm{pmol} / \mathrm{min} / \mathrm{mg}$ ). Accumulation of BPA sulfate was observed for $12 \mathrm{hr}$ to 4 days after $10 \mu \mathrm{M}$ BPA was added to a culture of NB-1 cells. These results suggest that $\mathrm{BPA}$ is partly detoxified by the sulfoconjugation reaction in human neuronal cells.

Key words brain, bisphenol A, NB-1, neuron, sulfotransferase

\section{INTRODUCTION}

Bisphenol A (BPA), one of the most prevalent environmental endocrine disrupters, has been extensively evaluated for toxicity in a variety of rodent models. In particular, the developmental and reproductive toxicity, as well as the carcinogenicity. ${ }^{1,2)}$ Since BPA is released from widely used polycarbonate plastics, we are frequently exposed to the compound in daily life. Due to its lipophilic structure, BPA is absorbed from the gut into the blood and crosses the blood-brain barrier with ease, whereby it can accumulate in the brain. However, little is known about its action on the central nervous system (CNS). Several reports have shown BPA to act on the CNS, especially in the fetus., ${ }^{3,4)}$ As prenatal action of estrogens or aromatizable steroids at the

\footnotetext{
*To whom correspondence should be addressed: Kyoritsu College of Pharmacy, 1-5-30, Shibakoen, Minatoku, Tokyo 1058512, Japan. Tel.: +81-35400-2634; Fax: +81-3500-2689; Email: tamura-hr@kyoritsu-ph.ac.jp
}

CNS is responsible for brain sexual differentiation, BPA might alter processes affecting sociosexual behavior through early CNS exposure.

BPA sulfate is a BPA metabolite found in rodent livers and human urine, in addition to BPA glucuronide. ${ }^{5,6)}$ We also have reported that Caco- 2 cells, a human colon carcinoma cell line, displayed a significant sulfotransferase (ST) activity toward BPA in vitro. ${ }^{7)}$ Since it has been esrtablished that BPA has effects on the CNS, we investigated whether BPA might be detoxified by sulfoconjugation in a human neuroblastoma cell line, NB-1.

\section{MATERIALS AND METHODS}

Materials - 5'-phosphoadenosine 3'-phospho $\left[{ }^{35} \mathrm{~S}\right]$ sulfate $\left(\left[{ }^{35} \mathrm{~S}\right] \mathrm{PAPS}\right)(82.78 \mathrm{Ci} / \mathrm{mmol})$ was purchased from NEN Dupont (Detroit, U.S.A.). Media and supplements for cell culture were purchased from GIBCO BRL (New York, U.S.A.). Snail sulfatase was purchased from Sigma (St. Louis, U.S.A.). Other reagents were obtained from Wako Chemicals (Tokyo, Japan).

Cell Culture — Human neuroblastoma cell line, NB-1, was obtained from Riken Cell Bank, Japan. Cells were grown in $5 \mathrm{ml}$ of the medium consisting of $45 \%$ Dulbecco's minimum essential medium (DMEM), 45\% RPMI1640, 10\% fetal bovine serum, $2 \mathrm{mM}$ glutamine, $10 \mathrm{U} / \mathrm{ml}$ penicillin and $10 \mathrm{U} / \mathrm{ml}$ streptomycin at $37^{\circ} \mathrm{C}$ in a humidified atmosphere containing $5 \% \mathrm{CO}_{2}$.

Preparation of Cytosolic Extracts from NB-1 Cells and Rat Brain - NB-1 cells $\left(1-2 \times 10^{7}\right)$ were removed from their culture dishes $\left(100 \mathrm{~mm}^{2}\right)$, washed with phosphate buffered saline, and then homogenized in $1 \mathrm{ml}$ buffer A $(50 \mathrm{mM}$ Tris- $\mathrm{HCl}$ (pH 7.5), $250 \mathrm{mM}$ sucrose, $0.1 \mathrm{mM}$ EDTA, $3 \mathrm{mM}$ 2-mercaptoethanol, $0.1 \mathrm{mM}$ phenylmethylsulfonyl fluoride, $5 \mu \mathrm{g} / \mathrm{ml}$ antipain, and $5 \mu \mathrm{g} / \mathrm{ml}$ pepstatin). The debris was removed by centrifugation at $3000 \times g$ for $15 \mathrm{~min}$, after which the supernatant was centrifuged at $105000 \times g$ for $60 \mathrm{~min}$. The clear lysate was used in the following studies. In order to prepare the rat brain and liver extracts, brains and livers were excised from 8-week Sprague-Dawley rats and homogenized in buffer A.

Assay of Phenol Sulfotransferase (P-ST) Activity _ Phenol sulfotransferase (P-ST) activity within each sample of lysate was determined using $\left[{ }^{35} \mathrm{~S}\right]$ PAPS as the sulfate donor, and BPA as the sulfate acceptor, according to a slight modification of 
(A)

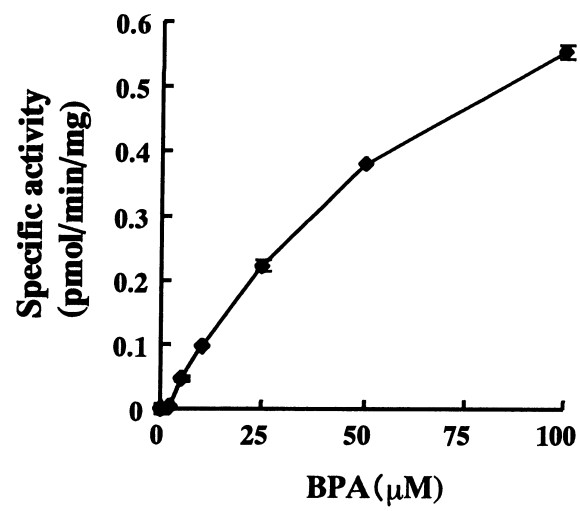

(B)

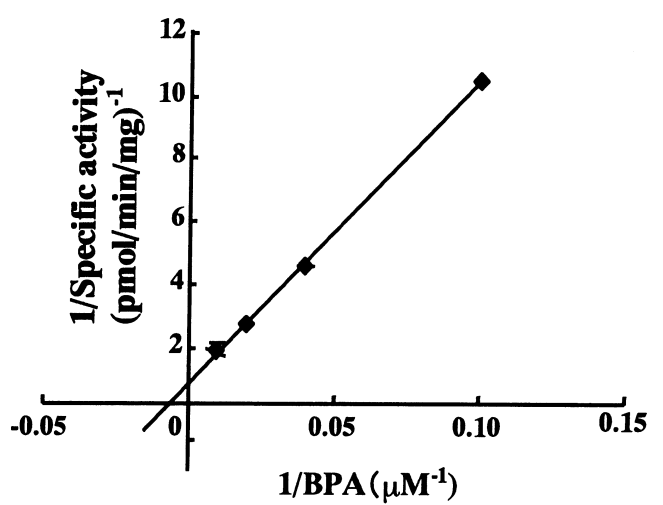

Fig. 1. ST Activity toward BPA in the Extract of NB-1 Cells

(A) ST activities were measured toward BPA ranging 3-100 $\mu \mathrm{M}$ using the NB-1 cell extract (50 $\mu \mathrm{g}$ proteins). Each point represents the mean \pm S.D. $(n=3)$. (B) Lineweaver-Burk plot of the results in (A). From three independent experiments, $\mathrm{Km}$ value and Vmax value were calculated to be $74 \pm 47 \mathrm{mM}$ and $7.8 \pm 4.5 \mathrm{pmol} / \mathrm{min} / \mathrm{mg}$ proteins, respectively.

the procedure of Foldes and Meek. ${ }^{8}$ Briefly, the reaction mixture $(250 \mu \mathrm{l})$ contained $10 \mathrm{mM}$ phosphate buffer (pH 7.4), $50 \mu \mathrm{M}$ BPA, $5.0 \mu \mathrm{M}\left[{ }^{35}\right.$ S]PAPS $(0.4 \mu \mathrm{Ci})$, and the cytosol extract ( $50 \mu \mathrm{g}$ of proteins). The mixture was incubated at $37^{\circ} \mathrm{C}$ for $30 \mathrm{~min}$ and the reaction was stopped by the addition of $50 \mu \mathrm{l}$ cold $0.1 \mathrm{M}$ barium acetate. Then, unconverted $\left[{ }^{35} \mathrm{~S}\right] \mathrm{PAPS}$ was precipitated by the addition of $50 \mu \mathrm{l}$ of both $0.1 \mathrm{M} \mathrm{Ba}(\mathrm{OH})_{2}$ and $0.1 \mathrm{M} \mathrm{ZnSO}_{4}$. The precipitate was removed by centrifugation at $12000 \times g$ for $5 \mathrm{~min}$. This precipitation procedure was then repeated. After the second round of precipitation, the remaining supernatant $(300 \mu \mathrm{l})$ was transferred to a $3 \mathrm{ml}$ liquid scintillator and the amount of radioactivity was counted. Controls were obtained by omitting the acceptor substrate from the reaction mixture.

Identification of BPA Sulfate on HPLC - To identify BPA sulfate on the HPLC, the rat liver cytosolic extact (5 $\mu \mathrm{g}$ proteins) was incubated with $100 \mu \mathrm{M}$ BPA and $20 \mu \mathrm{M}$ PAPS for up to $30 \mathrm{~min}$, and then the reaction mixture $(5 \mu \mathrm{l})$ was subjected to the HPLC analysis as described below. Reaction mixtures lacking either BPA or PAPS were used as controls. The reaction mixture was treated with 8 units of snail sulfatase for $30 \mathrm{~min}$, and then analyzed by HPLC.

Analysis of BPA sulfation in Intact NB-1 Cells

In order to examine the sulfation of BPA in intact NB-1 cells, BPA was added to the medium at a concentration of $1-10 \mu \mathrm{M}$, after which the cells were incubated at $37^{\circ} \mathrm{C}$. Aliquots $(100 \mu \mathrm{l})$ were removed at various times, and then $30 \mu \mathrm{l}$ of the mixture was filtered and injected into the HPLC. Analysis was performed using an ODS column (Chromolith Performance RP-18e, $100 \times 4.6 \mathrm{~mm} \phi$, Merck, Darmstadt, Germany). The mobile phase consisted of $10 \mathrm{mM}$ tetrabutylammonium hydrogen sulfate in water and acetonitrile $(79.5: 20.5)$. A flow rate of $1 \mathrm{ml} / \mathrm{min}$ was used with a column temperature of $40^{\circ} \mathrm{C}$. Fluorescence intensity was monitored at $313 \mathrm{~nm}$ with excitation of $273 \mathrm{~nm}$. The retention times for BPA and BPA sulfate were determined as $6.5 \mathrm{~min}$ and $14.5 \mathrm{~min}$, respectively. All signals representative of constituents of the medium were eluted prior to $5 \mathrm{~min}$.

\section{RESULTS AND DISCUSSION}

\section{ST Activity toward BPA in the NB-1 Cells}

In human tissue, two distinct forms of P-ST activity have been identified, phenol P-ST (P-PST) and monoamine P-ST (M-PST). ${ }^{9)}$ These enzymes are functionally distinct, based on differences in substrate and inhibitor specificities, as well as thermal stability. P-PST (a product of the SULTIAl gene) catalyzes sulfonation of simple phenols and is thermostable whereas M-PST (a product of SULT1A3 gene) preferentially catalyzes monoamines and is thermolabile. Previously we have reported NB-1 cells to express both SULT1 genes. ${ }^{10)}$ To determine whether NB-1 cells could sulfonate BPA, we measured ST activity toward BPA within the cell extract. As shown in Fig. 1, NB-1 cells showed significant ST activity toward BPA. Kinetic analyses of the ac- 
tivity is summarized in Table 1. NB-1 cells displayed a similar $\mathrm{Km}$ value $(74 \mu \mathrm{M})$ to that of the rat brain $(57 \mu \mathrm{M})$. As Suiko et al. have demonstrated efficient sulfonation of BPA by recombinant P-PST, ${ }^{5)}$ the PPST enzyme encoded by the SULTIAl gene might be responsible for the sulfonation observed in the present experiment.

\section{Sulfoconjugation of BPA in Intact NB-1 Cells}

To monitor the sulfoconjugation of BPA in NB1 cells in vivo, we synthesized BPA sulfate from a rat liver extract, followed by analy HPLC analysis. In addition to the peak presenting BPA (eluted at $6.5 \mathrm{~min}$ ), a second peak was observed at $14 \mathrm{~min}$, the size of which increased with increasing length of

Table 1. Kinetic Parameters of ST Activities toward BPA of NB-1 Cells and Rat Brains

\begin{tabular}{lcc}
\hline \hline cytosol & $\mathrm{Km}(\mu \mathrm{M})$ & Vmax $(\mathrm{pmon} / \mathrm{min} / \mathrm{mg})$ \\
\hline NB-1 & $74 \pm 47$ & $7.8 \pm 4.5$ \\
rat brain & $57 \pm 14$ & $27 \pm 12$ \\
\hline
\end{tabular}

All values are the mean of three experiments with S.D. incubation (Figs. 2A-2D). The appearance of the peak was PAPS-dependent and sensitive to sulfatase treatment, as shown in Figs. 2G and 2E, respectively. Based on these results, we identified the peak eluted at $14 \mathrm{~min}$ as BPA sulfate.

After adding 1 to $10 \mu \mathrm{M}$ BPA to the culture medium, the level of BPA sulfate within the culture medium was monitored. As shown in Fig. 3A, BPA sulfate first appeared at $12 \mathrm{hr}$, and increased up until 4 days in the case of $10 \mu \mathrm{M}$ BPA. Sulfonation of BPA within the cells occurred in a dose-dependent manner (Fig. 3B).

Here we described the ability of a neuroblastoma cell line, NB-1, to sulfonate BPA. Several reports have indicated the neurotoxicity of BPA. Orally administered BPA crosses the placental barrier with relative ease to reach the fetus. ${ }^{11}$ Exposure to BPA at a point in time when sexual differentiation of the brain normally occurs can influence adult behavior. The sulfoconjugative activity of neuronal cells as described in this report might ameliorate BPA toxicity within the CNS. If the P-PST activity is lower in fetal neuronal cells during the critical period of
(A) 0 min

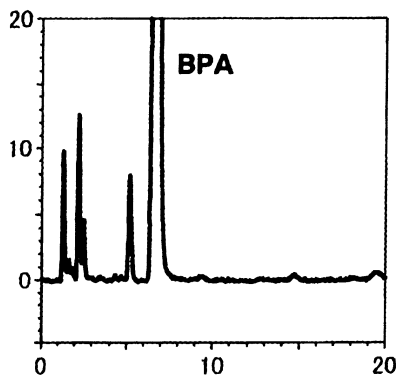

(E) sulfatase

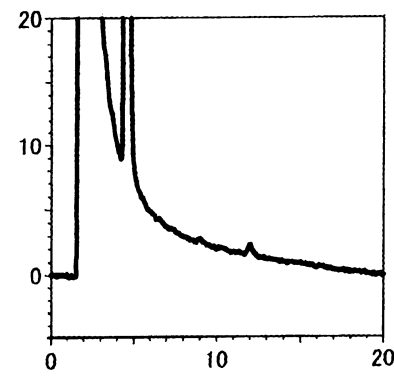

(B) 5 min

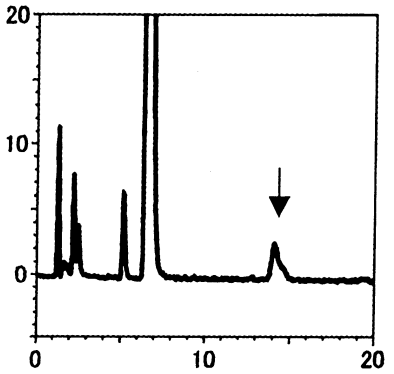

(F) BPA(-)

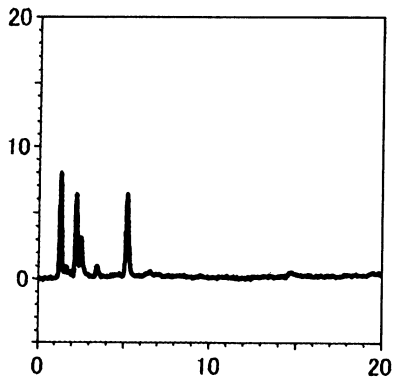

(C) $10 \mathrm{~min}$

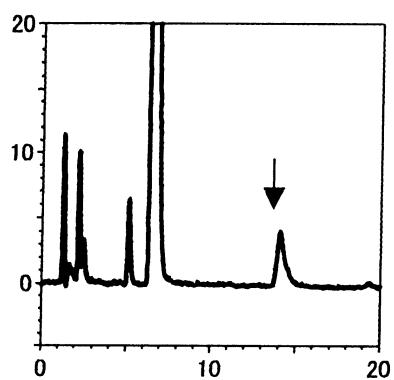

(G) PAPS(-)

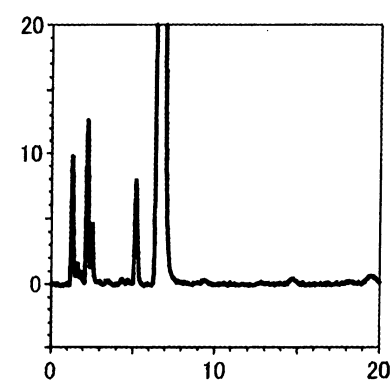

(D) $30 \mathrm{~min}$

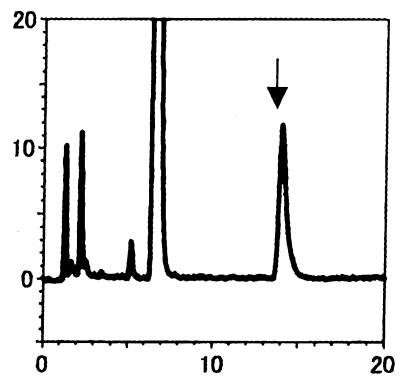

Fig. 2. HPLC Analysis of BPA Sulfate in the Rat Liver Cytosols

HPLC of BPA $(100 \mu \mathrm{M})$ incubated with the rat liver extract $(5 \mu \mathrm{g})$ for $0 \mathrm{~min}(\mathrm{~A}), 5 \mathrm{~min}(\mathrm{~B}), 10 \mathrm{~min}(\mathrm{C})$ and $30 \mathrm{~min}$ (D). (E) HPLC of the reaction mixture D treated with 8 units of snail sulfatase for $30 \mathrm{~min}$. (F, G) HPLC of the reaction mixture without either PAPS (F) or BPA (G), respectively. Arrows indicate the peak of BPA sulfate. 
(A)

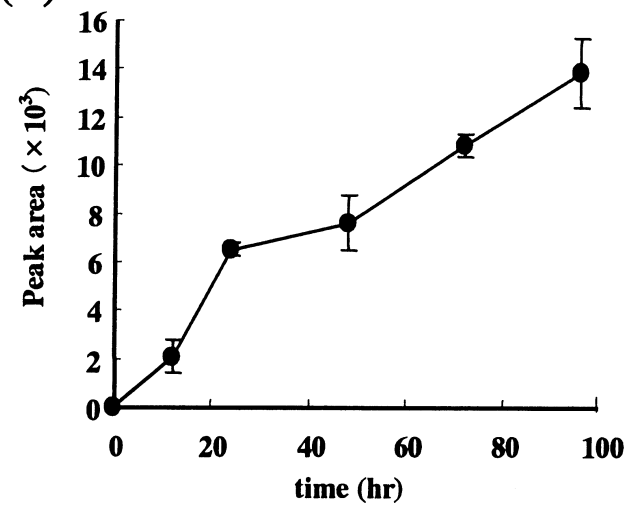

(B)

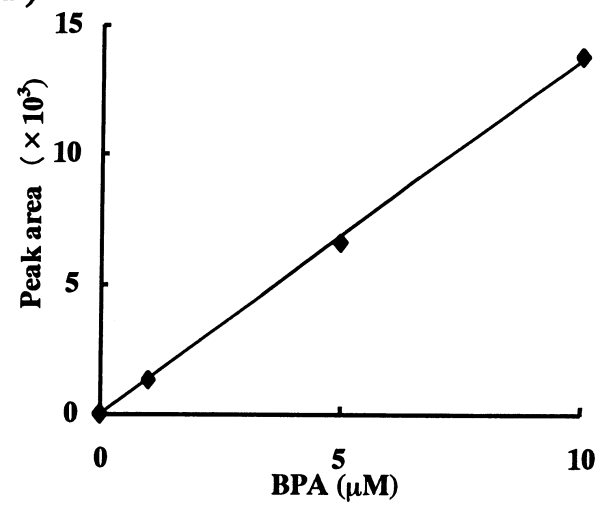

Fig. 3. Production and Secretion of BPA Sulfate in the NB-1 Cells

(A) Time course of BPA sulfation in the NB-1 cells. $10 \mu \mathrm{M}$ BPA was added to the culture medium and aliquots (100 $\mu$ l) were removed at the indicated times, and analyzed by HPLC. Each point represents the mean \pm S.D. of the peak area $(n=3)$. (B) Dose response of BPA for the sulfoconjugation reaction. BPA $(1-10 \mu \mathrm{M})$ was added to the medium and incubated for 5 days. Levels of BPA sulfates in the medium were measured by HPLC.

development, then BPA might affect the normal development of the brain of the fetus. Information regarding the level of P-PST activity within the fetal brain during development might contribute to this theory.

Only a $4 \%$ reduction in BPA (unconjugated) was observed in the culture medium containing $10 \mu \mathrm{M}$ BPA after 5 days incubation (data not shown). This result differs from that of a previous report by Pritchett et al. ${ }^{12)}$ in which a rapid loss of BPA from the culture medium of isolated rat hepatocytes was observed. Thus, we theorize that NB-1 cells may have either an active efflux transporter or a weak influx transporter for BPA. If so, this feature of the cells may explain why the NB-1 cells remained largely intact even in the presence of $50 \mu \mathrm{M}$ BPA for 5 days (data not shown). Since BPA sulfoconjugates account for 1-2\% of the initial BPA after 5 days culture (data not shown), which comprises $25-50 \%$ of the BPA taken up by the cells, it appears that BPA sulfoconjugation is a major metabolic pathway in neuronal cells. Since glucuronidation has been reported to be a major mean of metabolism of BPA in the rodent liver, ${ }^{13)}$ further investigation regarding the extent of glucuronidation of BPA in NB1 cells is needed.

Acknowledgements We are grateful to CREST Project on "Endocrine Disruptors in Synthesis and Action of Brain Neurosteroids" of Japan Promotion of Science and Technology. This work was supported in part by a Grant-in-Aid for Scientific Research from the Ministry of Education, Science, and Culture of Japan.

\section{REFERENCES}

1) Schantz, S. L. and Widholm, J. J. (2001) Cognitive effects of endocrine-disrupting chemicals in animals. Environ. Health Perspect., 109, 1197-1206.

2) Haighton, L. A., Hlywka, J. J., Doull, J., Lynch, B. S. and Munro, I. C. (2002) an evaluation of the possible carcinogenicity of bisphenol A to humans. Regul. Toxicol. Pharmacol., 35, 238-254.

3) Kubo, K., Arai, O., Ogata, R., Omura, M., Hori, T. and Aou, S. (2001) Exposure to bisphenol A during the fetal and sucking periods disrupts sexual differentiation of the locus coeruleus and of behavior in the rat. Neurosci. Lett., 304, 73-76.

4) Suzuki, T., Mizuno, K., Nakazawa, H., Funae, Y., Fushiki, S., Fukushima, S., Shirai, T. and Narita, M. (2003) Prenatal and neonatal exposure to bisphenolA enhances the central dopamine D1 receptor-mediated action in mice: Enhancement of the methamphetamine-induced abuse state. Neuroscience, 117, 639-644.

5) Suiko, M., Sakakibara, Y. and Liu, M.-C. (2000) Sulfation of environmental estrogen-like chemicals by human cytosolic sulfotransferases. Biochem. Biophys. Res. Commun., 267, 80-84.

6) Matsumoto, A., Kunugita, N., Kitagawa, K., Isse, T., Oyama, T., Foureman, G. L., Morita, M. and Kawamoto, T. (2003) Bisphenol A level in human urine. Environ. Health Perspect., 111, 101-104.

7) Tamura, H. and Matsui, M. (2001) Effects of phenolic environmental estrogens on the sulfotransferase activity of the mouse intestine and a human colon carcinoma cell line, Caco-2. J. Health Sci., 47, 468-472.

8) Foldes, A. and Meek, J. L. (1973) Rat brain phenolsulfotransferase - Partial purification and some 
properties. Biochim. Biophys. Acta, 327, 365-374.

9) Nagata, K. and Yamazoe, Y. (2000) Pharmacogenetics of sulfotransferase. Ann. Rev. Pharmacol. Toxicol., 40, 159-176.

10) Tamura, H., Taniguchi, K., hayashi, E., Hiyoshi, Y. and Nagai F. (2001) Expression profiling of sulfotransferases in human cell lines derived frm extrahepatic tissues. Biol. Pharm. Bull., 24, 1258-1262.

11) Miyakoda, H., Tabata, M., Onodera, S. and Takeda, K. (2000) Comparison of conjugative activity, conversion of bisphenol A to bisphenol A glucuronide, in feral anfd mature male rat. J. Health Sci., 46, 269-
274.

12) Pritchett, J. J., Kuester, R. K. and Sipes, I. G. (2002) Metabolism of bisphenol A in primary cultured hepatocytes from mice, rats, and humans. Drug Metab. Dispos., 30, 1180-1185.

13) Yokota, H., Iwano, H., Endo, M., Kobayashi, T., Inoue, H., Ikushiro, S. and Yuasa, A. (1999) Glucuronidation of the environmental oestrogen bisphenol A by an isoform of UGP-glucuronosyltransferase, UGT2B1, in the rat liver. Biochem. J., 340, 405-409. 